\title{
Diretrizes Curriculares da Educação Infantil: da teoria à prática pedagógica
}

\author{
Curriculum Guidelines for Early Childhood Education: from theory to pedagogical practice
}

Directrices Curriculares de la Educación Infantil: de la teoría a la práctica pedagógica

Leidryana da Conceição Ferreira ${ }^{1 *}$, Yolanda Aparecida de Castro Almeida Vieira².

\begin{abstract}
RESUMO
Objetivo: Descrever por meio de evidências científicas, o processo de implantação da Base Nacional Comum Curricular (BNCC) na pré-escola. Revisão Bibliográfica: Mostrar que não apenas a construção e a implantação de documentos norteadores determinam a qualidade do ensino brasileiro. É preciso que o professor também reveja o seu papel de mediador do conhecimento, por meio de uma prática pedagógica inovadora, que consiste em trabalhar a realidade vivenciada por seus alunos e realizar inúmeras pesquisas em busca de um método de ensino melhor. Considerações finais: Mais que a elaboração de um documento norteador, o ensino no Brasil precisa ser trabalhado de maneira unificada, mas, ao mesmo tempo, compatível com a realidade e a individualidade de cada aluno, ou ao menos de cada município. Assim, fazendo com que as experiências vivenciadas pelos estudantes sejam um ponto de partida para o processo de ensinoaprendizagem. Dessa forma, construindo um aprendizado significativo aos educandos e, consequentemente, aumentando a qualidade do ensino no Brasil.
\end{abstract}

Palavras-chave: Diretrizes, Pré-escola, Ensino, Aprendizagem, Pedagogia.

\begin{abstract}
Objective: Describe, through scientific evidence, the process of implementation of the National Curricular Common Base (BNCC) in preschool. Literature Review: Not only the construction and implementation of guiding documents determine the quality of Brazilian education. The teacher must also review his role as mediator of knowledge by means of an innovative pedagogical practice, which consists of working the reality experienced by his students and conducting countless researches in search of a better teaching method. Final considerations: More than the elaboration of a guiding document, teaching in Brazil needs to be worked in a unified way, but at the same time, compatible with the reality and individuality of each student, or at least of each municipality. Thus, making the experiences of each student are a starting point for the teaching-learning process. In this way, building a meaningful learning for students and, consequently, increasing the quality of teaching in Brazil.
\end{abstract}

Keywords: Guidelines, Preschool, Teaching, Learning, Pedagogy.

\section{RESUMEN}

Objetivo: Describir por medio de evidencias científicas, el proceso de implantación de la Base Nacional Común Curricular (BNCC) en la pre-escuela. Revisión Bibliográfica: Mostrar que no sólo la construcción y la implantación de documentos orientadores determinan la calidad de la enseñanza brasileña. Es necesario que el profesor también revise su papel de mediador del conocimiento, por medio de una práctica pedagógica innovadora, que consiste en trabajar la realidad vivenciada por sus alumnos y realizar innumerables investigaciones en busca de un método de enseñanza mejor. Consideraciones finales: Más que la elaboración de un documento orientador, la enseñanza en Brasil necesita ser trabajado de manera unificada, pero, al mismo tiempo, compatible con la realidad y la individualidad de cada alumno, o al menos de cada municipio. Así, haciendo que las experiencias vivenciadas por los estudiantes sean un punto de partida para

\footnotetext{
${ }^{1}$ Faculdade Vale do Cricaré São Mateus-ES. Brasil. *E-mail: leidryana@hotmail.com

2 Pontifícia Universidade Católica, Minas Gerais. Brasil.
} 
el proceso de enseñanza-aprendizaje. De esta forma, construyendo un aprendizaje significativo a los educandos y, consecuentemente, aumentando la calidad de la enseñanza en Brasil.

Palabras clave: Pautas, Preescolar, Enseñanza, Aprendizaje, Pedagogía.

\section{INTRODUÇÃO}

Mais de vinte anos se passaram desde que a Lei de Diretrizes e Bases (LDB) da Educação e os Parâmetros Curriculares Nacionais (PCNs) foram direcionados para a educação brasileira. Desde então, novas pesquisas sobre a Educação ocorreram e, com elas, novas propostas surgiram para o ensino no país. Diante da evolução que a educação brasileira vem passando, mais especificamente a Educação Infantil, ao longo desses anos, houve a construção e a implantação de documentos norteadores que definem conteúdos e objetivos a serem alcançados por seus alunos. Por anos o documento que direcionava os professores da Educação Infantil na prática pedagógica foi o Referencial Curricular Nacional da Educação Infantil (RCNEI) e, atualmente, a BNCC direciona o fazer pedagógico, estabelece que essa modalidade de ensino passa a ser a primeira etapa da Educação Básica (BRASIL, 2017).

Diante do trabalho com crianças cuja faixa etária varia de quatro (4) a seis (6) anos, o RCNEI (BRASIL, 1998) determina que devem ser consideradas "as ordens física, afetiva, cognitiva, ética, estética, de relação interpessoal e inserção social". Partindo do pressuposto de que as crianças nessa fase têm facilidade em desenvolver habilidades e criticidades que contribuem para a construção do aprendizado, o RCNEI prevê o trabalho voltado aos eixos norteadores: Natureza e Sociedade, Linguagem Oral e Escrita, Matemática, Música, Artes Visuais e Movimento (BRASIL, 1998).

Enquanto a BNCC, por sua vez, determina que para as crianças entre quatro (4) e cinco (5) anos consigam de fato a construção de um aprendizado significativo, elas precisam desenvolver o senso crítico e praticar atitudes de respeito e valorização ao ser humano e o meio ambiente. A Base também propõe que os educadores trabalhem com seus alunos predominando a interação e a brincadeira juntamente com os campos das experiências: O eu, o outro e o nós; Corpo, gestos e movimentos; Traços, sons, cores e formas; Escuta, fala, pensamento e imaginação; Espaços, tempos, quantidades, reações e transformações (BRASIL, 2017).

Os campos das experiências são fundamentados nos direitos de aprendizagens que a criança da Educação Infantil adquiriu com a BNCC. Cabendo, assim, ao professor da Educação Infantil garantir cada um dos seis (6) direitos de aprendizagem e desenvolvimento aos seus alunos: Conviver, Brincar, Participar, Explorar, Expressar, Conhecer-se. Direitos esses que permeiam além da construção do conhecimento sistematizado, estão atrelados ao senso crítico e reflexivo do aluno desta modalidade, para que a criança seja capaz de conhecer e compreender a si e o outro, de respeitar as diferentes culturas e de construir a própria independência (BRASIL, 2017).

Este artigo tem como objetivo abordar uma seleção de bibliografias que sustentam o processo de construção das Diretrizes Curriculares da Educação Infantil, bem como oferecer o suporte teórico aos educadores que atuam nessa modalidade.

\section{REVISÃO BIBLIOGRÁFICA}

O Ensino Infantil se tornou um campo de grandes pesquisas e revisões no mundo, partindo da pressuposição que se refere a uma das primícias para uma educação de qualidade. Por exemplo, no caso do Brasil, em 2010 as Diretrizes Curriculares Nacionais para a Educação Infantil (DCNEI) passaram por alterações, como: prever propostas curriculares para serem trabalhadas com crianças de quatro (4) a cinco (5) anos (de modo que possa ser dada continuidade no Ensino Fundamental, com o cuidado de não antecipar conteúdos que deverão ser tratados posteriormente); e propor o trabalho diversificado de acordo com a realidade local, com enfoque na diversidade e abordar a obrigatoriedade da matrícula de crianças que venham a completar quatro (4) ou cinco (5) anos até 31 de março do corrente ano (BRASIL, 2010). 
Em abril de 2017, considerando as versões anteriores da BNCC, o Ministério da Educação (MEC) concluiu a sistematização e encaminhou a terceira e última versão ao Conselho Nacional de Educação (CNE). Esse documento se deu por meio da implantação de uma política educacional articulada e integrada, visando a construção de um ambiente escolar propício ao aprendizado da criança de zero (0) a cinco (5) anos, partindo do princípio de que o desenvolvimento de habilidades e conhecimentos está vinculado às experiências familiar e social (BRASIL, 2017). De acordo com a BNCC, publicada pelo MEC, está busca implantar uma política educacional planejada e incorporada, construindo um ambiente escolar propício ao desenvolvimento da criança de zero (0) a cinco (5) anos, partindo do princípio de que o desenvolvimento de habilidades e conhecimentos está vinculado às experiências familiar e social que resultou em um conhecimento significativo (BRASIL, 2017).

Para nortear o fazer pedagógico na Educação Infantil, a BNCC estabelece que os educadores trabalhem de maneira unificada em todo território brasileiro, utilizando os campos de experiências. Trabalhar situações que contribuam para que as crianças construam um entrosamento, uma parceria entre elas, mas que também consigam estabelecer regras de convivência, respeitando e valorizando a individualidade do outro, para que assim passe existir o "nós" que está previsto no campo da experiência, que é a coletividade, o grupo social (BRASIL, 2017).

Desta maneira a BNCC propõe que se faça com as crianças da pré-escola um preparo, para fortalecer os conhecimentos que elas já trouxeram do ambiente familiar e aprimorá-los. Isso permitirá que elas se tornem aptas a intervirem na sociedade, com respeito e valorização do cidadão, independente de classe social, religião ou etnia (BRASIL, 2017).

A BNCC ressalta que a criança da Educação Infantil deve aprender a expressar o que pensa ou sente e, da mesma maneira, respeitar o que ouve do outro. Trata-se de saber que para o convívio em sociedade cada criança tem que desenvolver a sensibilidade, aprender a ter capacidade de se colocar no lugar do outro antes de falar ou julgar, aprender a refletir e a respeitar, mesmo que seja ela uma opinião ou cultura que se difere da que ela tem (BRASIL,2017).

Ter alunos que sejam capazes de desenvolver o senso crítico e praticar atitudes de respeito e valorização com o ser humano e o meio ambiente é um dos interesses que a BNCC tem para educação brasileira. Clarice C (2005) articula que a criança produz cultura, não pelos objetos ou relatos que constrói, mas pela formulação de um sentido que dá ao mundo que a rodeia.

De acordo com a BNCC as interações e a brincadeira, juntamente com as competências gerais da Educação Básica, devem ser respeitadas e seguidas pelo professor da Educação Infantil com o intuito de mediar o processo de ensino-aprendizagem, de forma prazerosa e produtiva. Utilizando as brincadeiras e a interação com os outros e com o meio em que está inserido, oportunizará ao aluno a construção do conhecimento significativo (BRASIL, 2017).

É dever do professor da Educação Infantil garantir cada um dos direitos de aprendizagem e desenvolvimento estabelecidos pela BNCC. Direitos esses que permeiam além da construção do conhecimento sistematizado, estão atrelados ao senso crítico e reflexivo do aluno desta modalidade, para que a criança seja capaz de conhecer e compreender a si e o outro, de respeitar as diferentes culturas e de construir a própria independência (BRASIL,2017).

\section{A educação infantil como primeira etapa da educação básica}

Com a inclusão da Educação Infantil a BNCC tem o papel decisivo na elevação da importância desta modalidade de ensino, pois de acordo com a própria BNCC a Educação Infantil passa a ser considerada como primeira etapa da Educação Básica e tida como um marco para a vida estudantil da criança (BRASIL, 2017). Desta maneira, a BNCC redireciona a educação brasileira.

A BNCC é um documento norteador para a Educação Básica do Brasil, direcionando metas e métodos que podem ser utilizados pelos educadores brasileiros conforme a necessidade percebida, no que se refere tanto à teoria quanto à prática pedagógica. Para Alves N (2015), esse documento estabelece propostas 
pedagógicas para cada modalidade de ensino, com fundamentação nos princípios da base nacional. Sendo assim, considerando-se que está propício a entrar em contradição com a realidade local, este documento propõe o trabalho entrelaçado entre conteúdos estabelecidos por ele e as experiências vivenciadas pelos alunos.

É válido refletir que a aprendizagem significativa só acontece de fato quando professor e aluno entrelaçam seus conhecimentos de mundo, às experiências trazidas por cada um. Desse modo, ambos irão adquirir, mutuamente, conhecimento concreto. E isso fará com que o aluno seja capaz de realizar uma leitura de mundo, desenvolvendo a criticidade do educando. Nessa seara, Piaget J (1970) explicita que a meta fundamental da educação dentro do ambiente escolar precisaria ser a de criar indivíduos, cidadãos, que tenham capacidade de inovar, de adquirir um senso crítico e não meramente reproduzir algo já existente.

Com base nesse panorama, é possível perceber que a BNCC traz atualmente para a Educação Infantil o papel inicial do processo de aprendizagem significativa, desta maneira atribuindo a essa modalidade a função de estimular o convívio social, o conhecimento, a criticidade, a autoconfiança e a liderança, além de fornecer subsídios às crianças para que se tornem adultos capazes de resolver os próprios conflitos e intervir positivamente na sociedade. Para Garcia RL (2005), nesse sentido, atribui à escola o papel de buscar métodos que quando permeados os conteúdos a cada realidade vivenciada pelos alunos resultem em aprendizado.

\section{O papel do professor da pré-escola na implantação da BNCC}

A implantação da BNCC no processo de ensino prevê algumas alterações para a educação brasileira, destacando-se, entre elas, a inclusão dos anos finais da Educação Infantil, a pré-escola, como parte da Educação Básica. Fundamentada, então, no fim da ruptura que existe quando o aluno passa da Educação Infantil para o Ensino Fundamental. Segundo as Diretrizes Curriculares Nacionais (DCNs) existe a necessidade de um percurso contínuo de aprendizagens de modo a articular as etapas de ensino, em especial da Educação Infantil para o Ensino Fundamental (BRASIL, 2010).

Referente a essa continuidade do processo de ensino-aprendizagem, Esteban MT (2005) afirma que a criança não vai à pré-escola para se preparar para aprender, ela vai para aprender e, enquanto esse aprendizado ocorre, consequentemente, esta criança também vai sendo habilitada para receber outros conhecimentos e aprendizados. A mesma autora ainda afirma que já existem saltos e rupturas no processo de aprendizagem dos alunos, atentando todos os envolvidos com a Educação Infantil ao cuidado que deve ser tomado quanto ao processo de ensino-aprendizagem de crianças muito pequenas, especificamente as da pré-escola, que dará sequência ao seu processo estudantil, com o ingresso ao Ensino Fundamental (ESTEBAN MT, 2005).

No mesmo sentido Garcia RL (2005) explana que na pré-escola é por meio de atividades lúdicas e criativas que as crianças adquirem o aprendizado e é por meio delas que os alunos vão se preparar para atividades futuras, como as aplicadas no Ensino Fundamental. Ela também chama a atenção de todos os atuantes da pré-escola brasileira, para que estejam atentos em não distorcerem a real função deste grupo de ensino, estando eles voltados para a construção e o desenvolvimento dos conhecimentos recentes e futuros dos alunos e aos métodos usados para isto.

A BNCC sugere para o campo de experiência o eu, o outro e o nós como ênfase nas relações, especialmente no que se refere ao respeito desde cedo. $E$ os conhecimentos adquiridos por meio das relações interpessoais são significativos, sendo formados com base em diferentes opiniões ou culturas. Embora também seja necessário trabalhar e respeitar a individualidade de cada aluno. Portanto, apresentar à criança a possibilidade de interagir com outras, a princípio pode ser um tanto assustador para ela, pois terá que entender que, na verdade, o mundo em que vive não se restringe apenas à sua casa, seu quarto, seus desejos e anseios. Isso não é fácil. Deste modo, cabe também ao professor, então, mediar essa transição da relação intrapessoal para a interpessoal, mostrando para essa criança que, embora a realidade de mundo não seja somente aquela na qual estava inserida, visto que é interessante conhecer algo ou alguém novo para ela, e isso pode ser uma experiência interessante e envolvente. 
Nessa perspectiva, Vygotsky (2007) afirma que ao longo do processo de desenvolvimento da criança existem apenas dois níveis que o determinam, o primeiro é entre pessoas (interpsicológica), o outro corresponde ao interior da criança.

Percebe-se que a construção do conhecimento humano acontece a todo momento, mesmo que involuntariamente. Não precisa, necessariamente, acontecer de forma mecanizada, pois por meio da brincadeira também se constrói conhecimento. Nesse sentido, Oliveira AE (2008) defende a utilização de brincadeiras como recurso didático para creches e pré-escolas. Nas palavras do autor, portanto, os jogos infantis vêm sendo defendidos como uma prática para estimular a aprendizagem e o desenvolvimento das crianças.

De maneira dinâmica, por meio da dança, dos jogos ou de brincadeiras a criança da pré-escola desenvolve capacidades de expressar seus sentimentos e sensações. Para facilitar o processo de desenvolvimento corporal dos alunos da pré-escola o professor deve dar ênfase às expressões corporais, danças, músicas, teatro. As crianças nessa faixa etária têm a necessidade de movimentar, de algo concreto que o traz sentido e prazer para aprender. São por meio de brincadeiras dirigidas que ocorrem novas competências, saberes e habilidades (WAJSKOP G, 1999).

A criança nesta faixa etária, de quatro (4) e cinco (5) anos, tem facilidade em criar e recriar por meio de brincadeiras, em especial quando envolve musicalidade, rimas e ritmos. Cabe ao professor usufruir desta característica para desenvolver as habilidades de escrita e oralidade, trabalhando a valorização por suas próprias produções e as dos colegas. Além disso, precisa permear a produção coletiva, em que cada um deverá considerar a opinião do outro para depois construir uma única produção, aprendendo, assim, além da construção da escrita textual a respeitar e valorizar a opinião dos outros. Trabalhar de maneira lúdica tende a facilitar o processo de construção do conhecimento do aluno, seu desenvolvimento pessoal, social e cultural (SANTOS PSM, 2000).

O constante contato com os escritos contribuirá para que as crianças conheçam e pratiquem a escrita e a oralidade de palavras ou textos de acordo com a norma culta. O reconto de história também é fundamental nessa fase de construção de conhecimentos pedagógicos, estimulando a prática de expressão verbal diante de público, favorecendo para que se tornem crianças desinibidas, capazes de expressar suas necessidades e sentimentos sem constrangimentos. Para expressar-se é preciso autoconfiança para manifestar os pensamentos e as emoções (PCN, 1997).

Ainda que as crianças usem bastante as linguagens oral e escrita, a forma como se expressam não se restringe somente a elas. O desenho e a pintura, por exemplo, também são muito utilizados por alunos da pré-escola que, deste modo, desenvolvem habilidades, permitindo que se expressem por meio da oralidade, da escrita, da pintura e do desenho. O processo de produção dessas técnicas, exige das crianças criatividade e concentração. Nessa fase o aluno, aos poucos, consegue substituir o rabisco por signos (VYGOTSKY LS, 1998).

A criança precisa mais do que conhecer e respeitar o espaço em que está inserida. Ela tem a necessidade de se relacionar com este, contribuindo para a conservação, independente se é a escola, a casa ou a própria natureza. Todos os espaços citados, dependem da ação humana para que seja estabelecida a conservação ou degradação desses espaços. O espaço reflete a cultura, demonstra traços da pessoa que ali vive (GANDINI L, 1999).

Conforme evidencia a BNCC (BRASIL, 2017), na fase final da Educação Infantil, os alunos da pré-escola já são capazes de desenvolver conhecimentos matemáticos que abrangem quantidades, medidas e espessuras, números, dentre outros. Para trabalhar com esses conteúdos, é fundamental que isso ocorra de maneira que o professor proporcione ao aluno o paralelo entre o concreto e o abstrato. De acordo com Piaget J (2003), o sujeito tem a capacidade de organizar o mundo de forma lógica ou operatória, não se limitando mais a uma representação imediata, mas ainda dependendo do mundo concreto para desenvolver a abstração. Garcia RL (2005) discorre que o desafio para a escola é o que e como pode ser feito para contribuir com que cada aluno, independentemente de classe, raça ou gênero, se capacite no decorrer de sua 
escolaridade. Observa-se, então, que para intervir no processo de aprendizagem do aluno, a princípio, o educador deve adotar uma conduta de pesquisador. Freire P (1996) demonstra, por meio de sua perspectiva teórica sobre esse tema, que o processo de ensino-aprendizagem e a pesquisa se correlacionam e completam, pois, um não existe sem o outro. $O$ autor frisa também a importância e as interferências que tem o ato da pesquisa, fazendo do momento do planejamento do professor, uma ocasião de pesquisa, de busca por conhecimentos para si e para seus alunos.

A conduta do educador pode ser decisiva para a formação do próprio conhecimento e o do aluno, quando o profissional se posiciona como pesquisador e inovador. Nesse sentido, Demo P (2006) vai além quando afirma que o professor precisa ser mais que pesquisador deve ser também socializador e motivador. Então, nota-se que é em meio a pesquisa que o educador descobre e constrói métodos que resultam em aulas mais dinâmicas, com envolvimento dos alunos e aprendizado significativo.

A aprendizagem significativa só acontece quando professor e aluno entrelaçam o conhecimento de mundo, às experiências trazidas por cada um. Assim, mutuamente, irão adquirir conhecimento concreto e isso fará com que o aluno seja capaz de realizar uma leitura de mundo, desenvolvendo sua criticidade. Nessa seara, Piaget J (1970) explicita que a meta fundamental da educação dentro do ambiente escolar precisaria ser a de criar indivíduos, cidadãos, que tenham capacidade construir novos conceitos alterando o que já existe não meramente reproduzi-los.

A BNCC traz atualmente para a Educação Infantil o papel inicial do processo de aprendizagem significativa, desta maneira atribuindo a essa modalidade a função de estimular o convívio social, o conhecimento, a criticidade, a autoconfiança e a liderança, além de fornecer subsídios as crianças para que se tornem adultos capazes de resolver os próprios conflitos e intervir positivamente na sociedade (BRASIL, 2017)

\section{CONSIDERAÇÕES FINAIS}

A ideia principal deste artigo é a de que em estudos futuros os órgãos competentes e pesquisadores da educação ao construírem, modificarem ou implantarem uma diretriz curricular reflitam e considerem a realidade vivenciada por alunos e professores de cada modalidade de ensino e de cada município. Esperase que, então, desta forma, seja possível facilitar a intercessão entre a teoria e a prática pedagógicas, resultando em qualidade e inovação no processo de ensino-aprendizagem. Todavia, embora isso não signifique que o educador em sua prática deva aderir a ela sem questionamento, até mesmo porque são os professores e os alunos que são o objeto de estudo. Neste caso, isso dá a eles o direito ao questionamento sobre a teoria, mesmo que isso seja por meio de uma legislação.

\section{REFERÊNCIAS}

1. ALVES N. Praticante pensante de cotidianos. 1aㅡ edição. Belo Horizonte: Autêntica Editora, 2015, p. 67, 71,139 e 1996.

2. BRASIL. Base Nacional Comum Curricular. Educação é a Base, Brasília, 2017.

3. BRASIL. Diretrizes Curriculares Nacionais Para a Educação Infantil. Brasília. 2010

4. BRASIL. Ministério da Educação e do Desporto. Secretaria de Educação Fundamental. Parâmetros Curriculares Nacionais: Língua Portuguesa. Brasília: MEC/SEF,1997.

5. BRASIL. Referencial Curricular Nacional da Educação Infantil: Conhecimento de Mundo, Brasília, 1998.

6. DEMO P. Pesquisa: princípio científico e educativo. São Paulo. Cortez. 2006.

7. ESTEBAN MT. Jogos de encaixe: educar ou formatar desde a pré-escola. In: edição. São Paulo, Cortez, 2005, p. 31-32. , Revisitando a pré-escola. $6^{\text {a }}$

8. FREIRE P. Pedagogia da Autonomia: Saberes necessários à prática educativa. São Paulo: Paz e Terra, 1996.

9. GANDINI L. Espaços Educacionais e de Envolvimento Pessoal. In: EDWARDS C; GANDINI L; FORMAN G. As cem linguagens da criança: a abordagem de RÉGGIO E. na educação da primeira infância. Porto Alegre: Artes Médicas Sul Ltda, 1999.

10. GARCIA RL (Org). Revisitando a pré-escola. 6ª edição. São Paulo, Cortez, 2005, p. 17, 19 e 23.

11. OLIVEIRA AE. A música onde está? Anais do VIII Congresso nacional de Federação de Arte-Educadores do Brasil. Florianópolis: UDESC, 2008. 
12. PIAGET JO. Nascimento da inteligência na criança. Rio de Janeiro, Zahar Editores. 1970.

13. PIAGET J. Seis estudos de psicologia. Tradução AMORIM, D', M, A, M e SILVA, P. S. L. 24 ed. Rio de Janeiro: Forense Universitária, 2003.

14. SANTOS PSM. Brinquedoteca: A criança, o adulto e o lúdico. Petrópolis. Rio de Janeiro: Vozes.

2000.

15. VYGOTSKY LS. A formação social da mente: O desenvolvimento de processos psicológicos superiores. São Paulo: Martins Fontes, 2007.

16. WAJSKOP G. Brincar na pré-escola. 3ª ed. São Paulo: Cortez, 1999. 